\title{
Protective Effects of Luteolin on Diabetic Nephropathy in STZ-Induced Diabetic Rats
}

\author{
Guo Guang Wang, ${ }^{1}$ Xiao Hua Lu, ${ }^{2}$ Wei Li, ${ }^{1}$ Xue Zhao, ${ }^{1}$ and Cui Zhang ${ }^{1}$ \\ ${ }^{1}$ Department of Pharmacology, Wannan Medical College, Wuhu 241002, China \\ ${ }^{2}$ Experimental Center for Function Subjects, Wannan Medical College, Wuhu 241002, China
}

Correspondence should be addressed to Guo Guang Wang, guoguangw1226@sina.com

Received 2 December 2010; Accepted 2 March 2011

Copyright ( $) 2011$ Guo Guang Wang et al. This is an open access article distributed under the Creative Commons Attribution License, which permits unrestricted use, distribution, and reproduction in any medium, provided the original work is properly cited.

\begin{abstract}
Diabetic nephropathy is a long-term complication of diabetic mellitus. Many experimental evidences suggest that persistent hyperglycaemia generates intracellular reactive oxygen species (ROS) and upregulates transforming growth factor-b1 and extracellular matrix expression in mesangial and tubular epithelial cells, which is involved of free radicals in the pathogenesis of diabetes and more importantly in the development of diabetic complications. Antioxidants effectively inhibit high-glucose- and $\mathrm{H} 2 \mathrm{O} 2$-induced transforming growth factor-b1 and fibronectin upregulation, thus providing evidence that ROS play an important role in high glucose-induced renal injury. The flavonoid luteolin has been shown to possess direct antioxidant activity, therefore we hypothesize that it may be useful in treatment of many chronic disease associated with oxidative stress, such as diabetic nephropathy via its antioxidant properties. Our results suggested that protection against development of diabetic nephropathy by luteolin treatment involved changes in superoxide dismutase (SOD) activity, the malondialdehyde (MDA) content and expression of Heme Oxygenase-1 (HO-1) protein.
\end{abstract}

\section{Introduction}

Herbal medicines are naturally occurring, plant-derived substances with minimal or no industrial processing that have been used to treat illness within local or regional healing practices. For a long time, herbal medicines or their extracts have been used to cure various diseases [1-3], because plant products are frequently considered to be less toxic and more free from side effects than synthetic ones [4]. Luteolin, a plant-derived flavonoid, has a variety of biological activities including well-known anti-inflammatory [5], antimutagenic, and antitumorigenic [6] properties. Moreover, it possesses direct antioxidant activity [7], which may be useful in treatment of many chronic disease associated with oxidative stress, such as cardiovascular diseases [8, 9], liver diseases [10,11], diabetes [12], and aging [13]. Glucose uptake and utilisation by peripheral tissues, such as liver, muscle, and fat, is crucial for maintaining normal blood glucose level.

Many experimental evidences suggest the involvement of free radicals in the pathogenesis of diabetes [14] and more importantly in the development of diabetic complications $[12,15,16]$. Free radicals are capable of damaging cellular molecules, DNA, proteins, and lipids leading to altered cellular functions. Many recent studies reveal that antioxidants capable of neutralizing free radicals are effective in preventing experimentally induced diabetes in animal models $[17,18]$ as well as reducing the severity of diabetic complications [16].

Diabetic nephropathy is one of the most serious complications of diabetes and the most common cause of end-stage renal failure. At present, diabetic kidney disease affects about $15 \%-25 \%$ of type I diabetes patients [19] and $30 \%-40 \%$ of patients with type II diabetes [20]. Diabetic nephropathy is characterized by specific renal morphological and functional alterations. ROS play an important role in high glucoseinduced renal injury $[21,22]$. Flavonoids are abundant plant phenolic compounds. More than 6000 have been identified to date, and some have been shown to possess hypoglycemic and antidiabetic activities [23]. There is no report on luteolin relating to protective role on diabetic nephropathy. Therefore, the present study was aimed at determining 
the protective effects of luteolin on diabetic nephropathy in STZ-induced DM.

\section{Methods}

All experiments were performed in accordance with the Guide for the Care and Use of Laboratory Animals of the Chinese National Institutes of Health. Forty male SpragueDawley rats, weighing $180-220 \mathrm{~g}$, were procured from an authorized firm in Nanjing, China. They were housed in a standard animal facility under controlled environmental conditions at room temperature $22 \pm 2^{\circ} \mathrm{C}$ and 12-hour lightdark cycle and received a standard pellet diet and water ad libitum. At the beginning of the experimental period, rats were assigned randomly into four groups: the control group given a standard chow diet, the control group given a luteolin diet, the diabetic group given a standard chow diet, and the diabetic group given a luteolin diet. Type I diabetes was induced as described previously [24]. Briefly, diabetes mellitus was induced by a single intraperitoneal injection of streptozotocin (STZ, $70 \mathrm{mg} / \mathrm{kg}$ ) dissolved in $0.1 \mathrm{M}$ citrate buffer ( $\mathrm{pH} 4.5)$ in male Sprague-Dawley rats. The control group rats were treated with the same volume citrate buffer. Diabetes was confirmed at $48 \mathrm{~h}$ after STZ injection by measuring the glucose concentrations of peripheral blood obtained from the tail vein (One Touch SureStep Meter, LifeScan, Calif, USA). All animals had free access to food and water. Diabetes was diagnosed by a sustained glucose concentration $>15 \mathrm{mmol} / \mathrm{L}$. After diabetes was confirmed, luteolin feeding was started at a dose of $200 \mathrm{mg} / \mathrm{kg}$ dissolved in distilled water using an intragastric tube. The rats were anaesthetized with pentobarbital sodium and sacrificed eight weeks after confirming high blood glucose level. Blood samples and kidney were collected for biochemical analyses. A 24-h urine was collected on the day before the blood sample and aliquots were taken.

2.1. Biochemical Analyses. Blood samples for the measurement of blood chemistry were drawn into prechilled EDTAcontaining tubes and immediately placed on ice. Blood samples were centrifuged at $2300 \mathrm{~g}$ for separation of serums and stored at $-70^{\circ} \mathrm{C}$ until assay. Serums were used for the estimation of glucose, 24-h urea protein, blood urea nitrogen (BUN), and creatinine as described previously [24, 25]. The levels of serum triacylglycerol (TG), total cholesterol (TC), high density lipoprotein (HDL), and low density lipoprotein (LDL) were measured as previously described [26]. Lipids in livers such as TC and TG were also estimated by the abovementioned methods.

\section{Antioxidant Measurement}

Kidney homogenate $(10 \%, \mathrm{w} / \mathrm{v})$ was prepared with $0.1 \mathrm{M}$ PBS and centrifuged at $12000 \mathrm{~g}$ for $10 \mathrm{~min}$. The supernatant was used to determine superoxide dismutase (SOD) activity and Malondialdehyde (MDA) levels with commercially available kits (Nanjing Jiancheng Bioengineering Institute).
TABLE 1: Weight changes of the rats.

\begin{tabular}{lccl}
\hline & Initial $(\mathrm{g})$ & Final $(\mathrm{g})$ & \\
\hline Control group & $190.1 \pm 9.5$ & $386.1 \pm 25.7$ & $P<.001$ \\
Control luteolin group & $189.4 \pm 10.2$ & $383.9 \pm 23.5$ & $P<.001$ \\
DM group & $195.9 \pm 11.0$ & $169.6 \pm 12.8$ & $P<.001$ \\
DM luteolin group & $194.3 \pm 13.0$ & $201.3 \pm 17.8$ & \\
\hline
\end{tabular}

TABLE 2: Change of Blood glucose.

\begin{tabular}{lccc}
\hline & $48 \mathrm{~h}(\mathrm{mmol} / \mathrm{L})$ & 8 weeks $(\mathrm{mmol} / \mathrm{L})$ & \\
\hline Control group & $5.06 \pm 0.47$ & $5.51 \pm 0.82$ & \\
Control luteolin group & $4.98 \pm 0.56$ & $5.31 \pm 0.83$ & \\
DM group & $22.25 \pm 2.56$ & $21.48 \pm 2.28$ & \\
DM luteolin group & $21.73 \pm 2.59$ & $13.66 \pm 1.84$ & $P<.01$ \\
\hline
\end{tabular}

3.1. Luteolin on Histology. At the end of followup, all rats were euthanized with high-dose pentobarbital. The kidneys were immediately removed and fixed in $4 \%$ neutral formalin for 2 hours. Three short-axis slices of renal tissue were obtained and embedded in paraffin. Sections were cut at $4 \mathrm{~mm}$ with a microtome and deparaffined with xylene. They were stained with Hematoxylin-Eosin (H-E) staining. Stained kidney sections were observed under a light microscope at magnifications of 400x.

3.2. Luteolin on Heme Oxygenase-1 and Phosphorylated Akt. Kidney samples $(0.2 \mathrm{~g})$ were lysed and homogenized in $2 \mathrm{~mL}$ of lysis buffer (10 mM Tris-buffered saline, $1 \mathrm{mM}$ EDTA, $1 \mathrm{mM}$ EGTA, $2 \mathrm{mM}$ sodium orthovanadate, $0.2 \mathrm{mM}$ PMSF, $2 \mu \mathrm{g} / \mathrm{mL}$ leupeptin, $2 \mu \mathrm{g} / \mathrm{mL}$ aprotinin, and $1 \%$ Triton X100) for $30 \mathrm{~min}$ on ice and cleared by centrifugation at $13,000 \mathrm{~g}$ for $15 \mathrm{~min}$ at $4^{\circ} \mathrm{C}$. Total protein concentration was determined in the supernatant using the Bradford assay (BioRad Laboratories, Hercules, Calif, USA). For each lane, equal amounts of protein were mixed with sodium dodecyl sulfate (SDS) sample buffer and boiled for 5 minutes. Samples were separated on a $10 \%$ sodium dodecyl sulfatepolyacrylamide gel and then transferred to $0.2-\mu \mathrm{m}$ nitrocellulose membrane. Nitrocellulose blots were blocked by incubation in TBST (10 mM Tris- $\mathrm{HCl}, \mathrm{pH} 7.5,150 \mathrm{mM} \mathrm{NaCl}$, and $0.1 \%$ Tween 20) containing 5\% nonfat milk for $1 \mathrm{~h}$ at room temperature and then incubated with a rabbit polyclonal anti-Heme oxygenase-1 (HO-1), AKT/PKB, phospho-AKT/PKB, $\beta$ actin antibody (1:500 dilution) overnight at $4^{\circ} \mathrm{C}$. After 3 washing steps, a secondary antirabbit antibody $(1: 10,000$ dilution) was added and incubated for 1 hour. After rinsed with wash buffer for three times, the reaction was visualized by DAB.

3.2.1. Statistical Analysis. All values are expressed as mean \pm s.e.m. Statistical evaluation was done using one way analysis of variance (ANOVA) followed by Duncan's multiple range test (DMRT) by using SPSS 11.09 for windows. The significance level was set at $P<.05$. 
TABLE 3: Biochemical analysis in blood.

\begin{tabular}{lccc}
\hline & BUN $(\mathrm{mmol} / \mathrm{L})$ & Creatinine $(\mathrm{mmol} / \mathrm{L})$ & $24-\mathrm{h}$ urea protein $(\mathrm{mg})$ \\
\hline Control group & $4.67 \pm 0.55$ & $45.06 \pm 4.49$ & $4.38 \pm 0.94$ \\
Control luteolin group & $4.51 \pm 0.47$ & $43.83 \pm 4.76$ & $4.26 \pm 0.63$ \\
DM group & $14.59 \pm 0.76^{* *}$ & $89.15 \pm 6.26^{* *}$ & $36.41 \pm 4.51^{* *}$ \\
DM luteolin group & $8.82 \pm 0.80^{\# \#}$ & $65.08 \pm 5.32^{\# \#}$ & $12.61 \pm 2.54^{\# \#}$ \\
\hline
\end{tabular}

Values are expressed as mean \pm SD of eight samples from each group. ${ }^{* *} P<.01$, significantly different from control group and control luteolin group. ${ }^{\# \#} P<$ .01 , significantly different from DM group.

TABLE 4: Change of serum lipids profile.

\begin{tabular}{lcccc}
\hline Groups & TC $(\mathrm{mmol} / \mathrm{L})$ & TG $(\mathrm{mmol} / \mathrm{L})$ & LDL $(\mathrm{mmol} / \mathrm{L})$ & HDL $(\mathrm{mmol} / \mathrm{L})$ \\
\hline Control group & $1.53 \pm 0.29$ & $0.71 \pm 0.14$ & $2.02 \pm 0.43$ & $1.35 \pm 0.23$ \\
Control luteolin group & $1.48 \pm 0.24$ & $0.69 \pm 0.13$ & $2.12 \pm 0.40$ & $1.31 \pm 0.25$ \\
DM group & $5.60 \pm 0.71^{* *}$ & $2.65 \pm 0.51^{* *}$ & $7.04 \pm 0.85^{* *}$ & $0.41 \pm 0.13^{* *}$ \\
DM luteolin group & $2.62 \pm 0.35^{\# \#}$ & $1.05 \pm 0.14^{\# \#}$ & $3.47 \pm 0.58^{\# \#}$ & $0.74 \pm 0.17^{\# \#}$ \\
\hline
\end{tabular}

Values are expressed as mean \pm SD of eight samples from each group. ${ }^{* *} P<.01$, significantly different from control group and control luteolin group. ${ }^{\# \#} P<$ .01 , significantly different from DM group.

\section{Results}

In this study, the STZ-treated diabetic rats developed uncontrolled type 1 diabetes mellitus. Rats that had received streptozotocin became diabetic at a frequency of $80 \%$. All the rats had well-developed signs of diabetes after 2 weeks of STZ administration, that is, hyperglycaemia, glycosuria, polyuria, increased water consumption, and weight loss. Diabetes was associated with reduced body weight when compared with the control rats. Changes in initial and final body weight (BW) of normal control and experimental groups are shown in Table 1. As expected, marked BW loss was observed in diabetic rats. However, luteolin treatment appeared to protect the diabetic rats from massive BW loss. Luteolintreated rats showed a recovery in final BW which was close to that of normal control rats.

4.1. Biochemical Finding. Blood glucose level was very high in DM group and DM luteolin group in $48 \mathrm{~h}$ after STZ injection. After 8 weeks, treatment with luteolin showed a significant fall of blood glucose level in diabetic rats (Table 2). BUN, serum creatinine, and 24-h urea protein were measured, and the results are shown in Table 3. The levels of BUN, $24 \mathrm{~h}$ urea protein, and creatinine were significantly increased in STZ-induced diabetic rats when compared with those of normal control rats treated and untreated with luteolin. Administration of luteolin at $200 \mathrm{mg} / \mathrm{kg}$ to diabetic rats tends to bring the values to near normal. The levels of blood urea nitrogen, $24 \mathrm{~h}$ urea protein, and creatinine were significantly decreased.

4.1.1. Serum and Tissue Lipids Profile. Effects of treatment with luteolin to diabetic rats on serum lipids like TC, TG, serum high density lipoprotein (HDL), and low-density lipoprotein (LDL) are presented in Table 4. As was shown in Table 4 that the levels of serum TC, TG, and LDL were significantly increased in diabetic rats when compared with those of normal control rats, while the level of serum HDL
TABLE 5: Change of kidney lipids profile.

\begin{tabular}{|c|c|c|}
\hline & $\begin{array}{c}\text { TC (mg per g } \\
\text { protein) }\end{array}$ & $\begin{array}{c}\text { TG (mg per g } \\
\text { protein) }\end{array}$ \\
\hline Control group & $5.74 \pm 0.37$ & $4.51 \pm 0.34$ \\
\hline Control luteolin group & $5.68 \pm 0.35$ & $4.39 \pm 0.35$ \\
\hline DM group & $10.90 \pm 0.78^{* *}$ & $10.68 \pm 0.75^{* *}$ \\
\hline DM luteolin group & $6.79 \pm 0.69^{\# \#}$ & $6.14 \pm 0.48^{\# \#}$ \\
\hline
\end{tabular}

Values are expressed as mean \pm SD of eight samples from each group. ${ }^{* *} P<.01$, significantly different from control group and control luteolin group. ${ }^{\# \#} P<.01$, significantly different from DM group.

was significantly decreased in diabetic rats when compared to that of normal control rats. The serum lipids like TC, TG, and LDL were significantly decreased and HDL was significantly increased in diabetic rats treated with luteolin when compared with those of diabetic rats.

Furthermore, there were significant increases of TC and TG in kidney in STZ-induced diabetic rats when compared to those of normal control rats. On the other hand, TC and TG levels in kidney were significantly decreased in diabetic rats treated with luteolin when compared to those of diabetic rats (Table 5).

4.2. Antioxidant Effects of Luteolin. As shown in Figure 1, SOD activity was significantly decreased and MDA level significantly increased in the kidney of STZ-induced diabetic rats when compared with those in normal control rats. Luteolin significantly enhanced SOD activity and reduced MDA level in kidney homogenates.

4.3. Histopathological Finding. Diabetic nephropathy is characterized by an expansion of glomerular mesangium, which is caused by mesangial cell proliferation and excessive accumulation of ECM [27]. As demonstrated in Figure 2, in the normal rats, the outer cortical glomerulus was of normal size and configuration. Moreover, the mesangium contained 


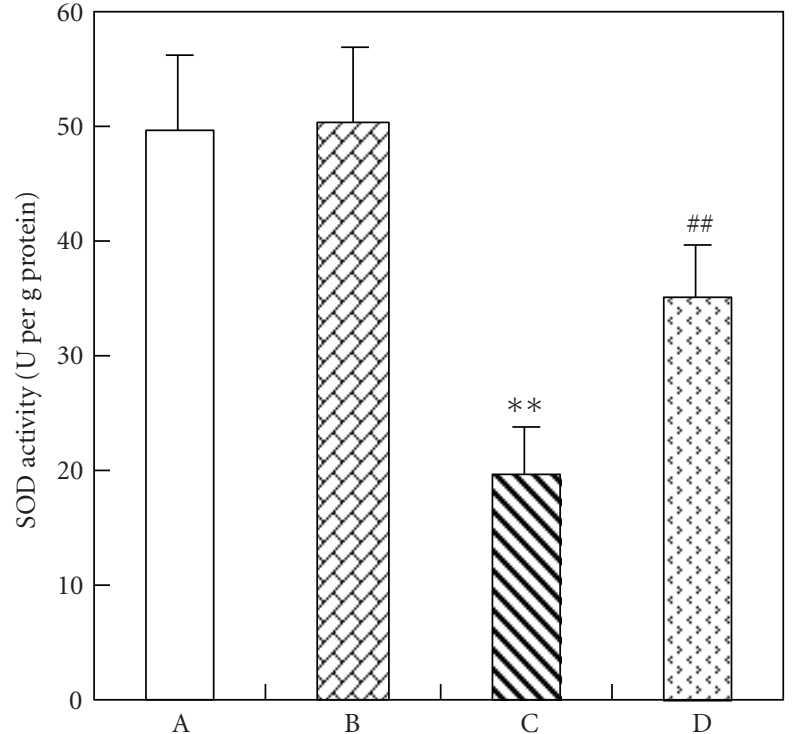

(a)



(b)

FIGURE 1: Changes of antioxidant effects in the kidney of each group. (A) Control rat. (B) Control rat with luteolin. (C) Diabetic rat. (D) Diabetic rats with luteolin. The kidney specimen of the diabetic group showed a markedly decrease of SOD activity and increase of MDA content $(\mathrm{C}) .{ }^{* *} P<.01$, significantly different from control group and control luteolin group. ${ }^{\# \#} P<.01$, significantly different from DM group.

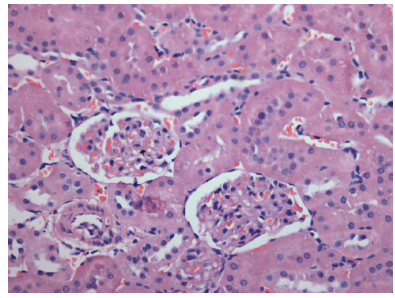

(a)

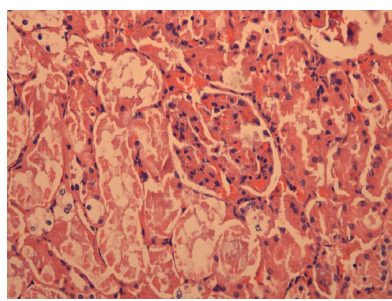

(c)

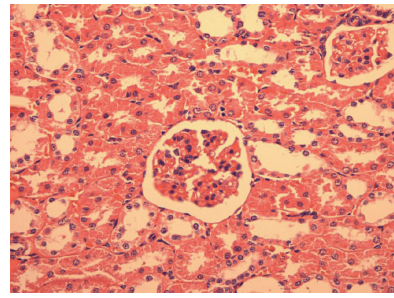

(b)

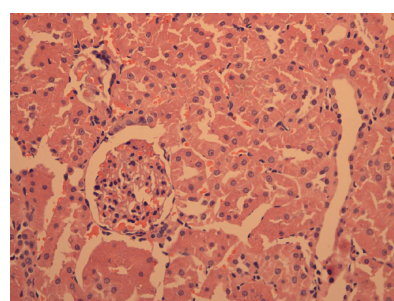

(d)
Figure 2: Photomicrographs of H-E staining in the kidney of each group. (a) Control rat. (b) Control rat with luteolin. (c) Diabetic rat. (d) Diabetic rats with luteolin. The kidney specimen of the diabetic group showed markedly severe destruction in glomerular and tubulointerstitial lesions such as glomerular sclerosis atrophy, interstitial expansion, and interstitial cellular infiltration (c). General morphology of glomerulus and tubulointerstitial lesions were much improved and showed quite normal appearance.

the usual complement of cells and matrix without ECM accumulation. The glomeruli from diabetic rat kidneys were dramatically different in appearance.
Western Blot. Our data show a significant increase expression of $\mathrm{HO}-1$ protein in diabetic rat kidneys compared with that in the normal. Treatment with luteolin to diabetic rats increased expression of HO-1 protein (Figure 3 ). We also documented the fall of serine- 473 phosphorylation of $\mathrm{AKT} / \mathrm{PKB}$ in diabetic rat kidneys compared to that in the normal rat kidneys. Luteolin treatment increased AKT/PKB phosphorylation in diabetic rat kidneys compared with that in the untreated diabetic rat kidneys (Figure 3).

\section{Discussion}

In the presence study, we provide evidence that protection against the development of diabetic nephropathy by luteolin treatment involves changes in the expression of HO-1 and p-Akt. Our results show that luteolin treatment prevented the development of diabetic nephropathy by significantly lowering BUN and creatinine in diabetic animals. Luteolinfed rats had less renal injury. This could be explained that there was increased clearance of blood urea and creatinine by the kidney or that there was decreased protein degradation. Moreover, luteolin also prevented the increase in 24-h urea protein in diabetic rats.

Increased polyol pathway activity induced by hyperglycaemia has been reported to contribute to abnormalities such as increased osmotic and oxidative stress factors that have been cited as promoters of diabetic microvascular diseases including diabetic nephropathy [28]. High plasma MDA level and decreased SOD activity are found in diabetes [29]. Antioxidants (e.g., vitamins C and E) protect against the development of diabetic nephropathy [30]. Various biological actions of luteolin are mediated by inhibiting 

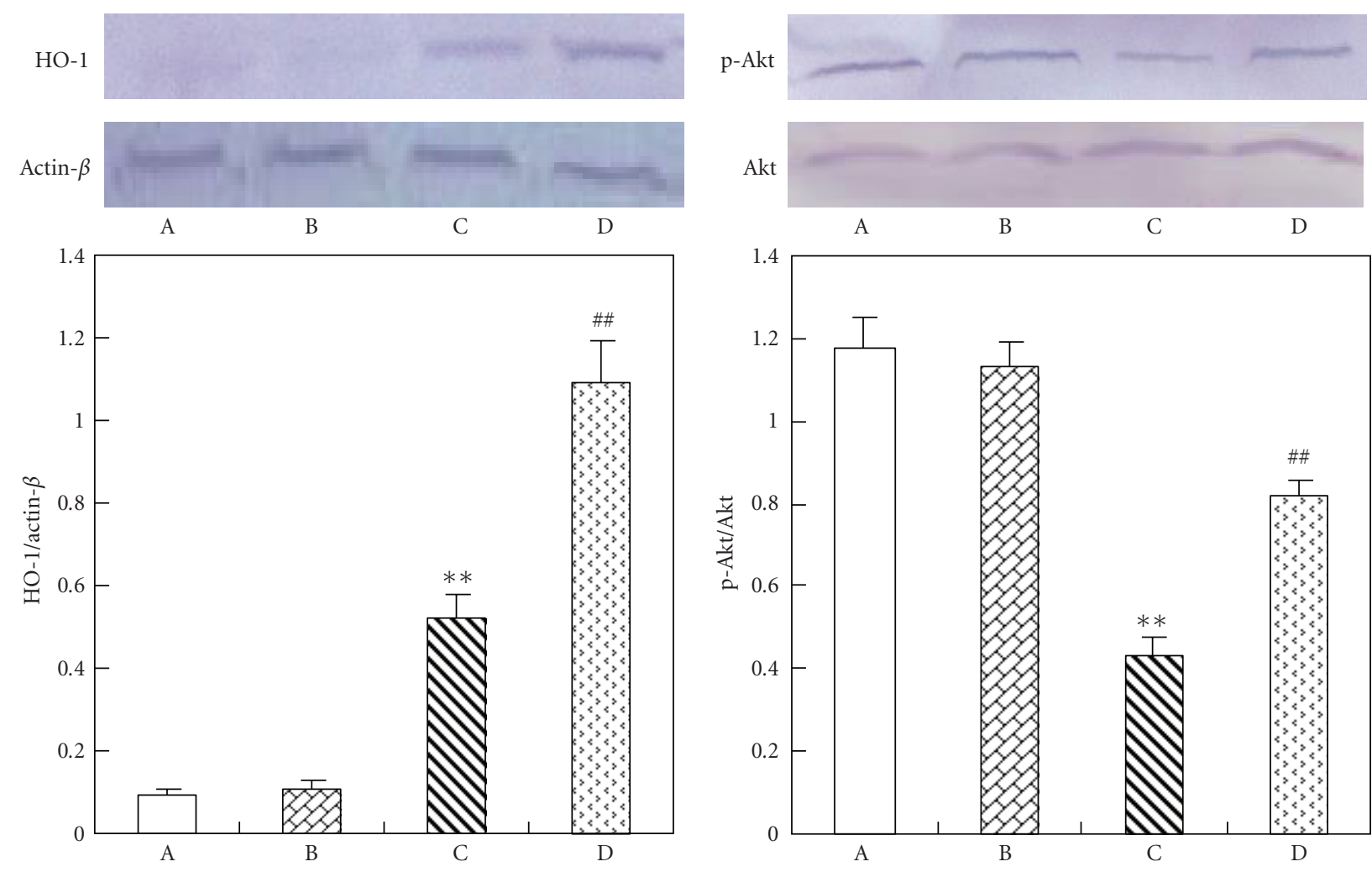

(a)
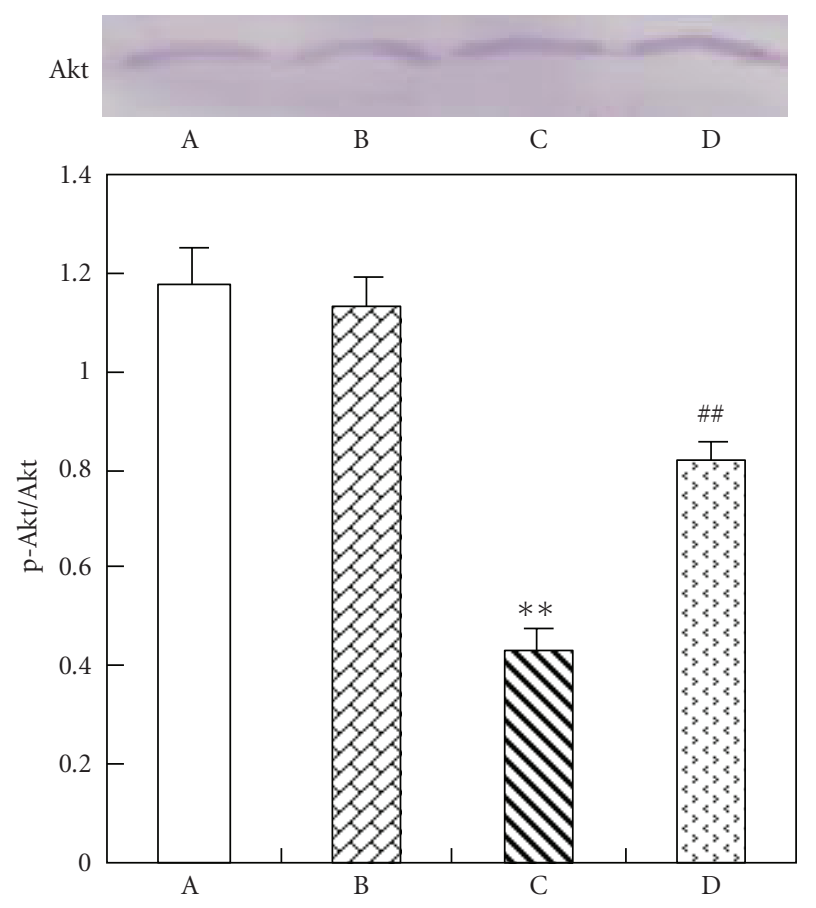

(b)

Figure 3: Western blot analysis in the kidney of each group. (A) Control rat. (B) Control rat with luteolin. (C) Diabetic rat. (D) Diabetic rats with luteolin. The kidney specimen of the diabetic group showed markedly a elevated expression of HO-1 and decreased p-Akt (C). ${ }^{* *} P<.01$, significantly different from control group and control luteolin group. ${ }^{\# \#} P<.01$, significantly different from DM group.

oxidative stress [7] and inflammation [5]. Moreover, luteolin has been reported to mediate its effects by modulating several important molecular targets, including transcription factors (nuclear factor-kB and activating protein-1) [31], enzymes (inducible nitric oxide synthase inhibitor) [32], and cytokines (tumour necrosis factor-a, interleukin1 , interleukin-6, and chemokines) [33]. In present study, luteolin was found to decreased MDA level and increased SOD activity in kidney homogenate.

The abnormal high concentration of serum lipids is mainly due to increase in the mobilization of free fatty acids from the peripheral fat deposits, because insulin inhibits the hormone sensitive lipase production. Therefore, the elevated level of serum lipids in DM causes the risk of diabetic nephropathy $[34,35]$. It has been well established that DM alters the normal metabolism of tissues like kidney. The administration of luteolin to diabetic rats tends to bring the values to near normal. Luteolin is known to have antioxidant properties [7], and this may reduce the susceptibility of lipids to oxidation and stabilize the membrane lipids, thereby reducing oxidative stress. However, administering luteolin to diabetic rats tends to bring the values to near normal. Thus, luteolin treatments exhibited hypocholesterolaemic, hypotriglyceridaemic, and hypophospholipidaemic effects while at the same time increasing the HDL.
Increased plasma creatinine level and BUN are indications of the development of diabetic nephropathy in diabetic rats $[36,37]$. BUN and creatinine levels are higher in rats with diabetic nephropathy than those in normal rats [38]. Maintenance of these biochemical variables closer to those in control rats by luteolin treatment suggests that luteolin plays a role, either directly or indirectly, in providing protection against diabetic nephropathy or delay in its development.

Heme oxygenase-1 (HO-1), the inducible isoform of the $\mathrm{HO}$ system, is a rate-limiting enzyme which converts heme into equimolar amounts of iron, carbon monoxide, and biliverdin. HO-1 is thought to have antioxidant and cytoprotective roles [39]. The products of the HO reaction, biliverdin, and carbon monoxide can be toxic at very high concentrations. However, recent evidence indicates that they are not toxic at physiological concentrations in normal cells and that they may also have important antioxidant, anti-inflammatory, or anti-apoptotic properties [40, 41]. AKT protein is a serine/threonine kinase and a downstream effector of PI3-K. It plays a crucial role in a variety of cellular events such as apoptosis, cell cycle progression, and transcriptional regulation [42]. The recent studies indicated that the activated AKT account for the modulation of cardiac function [43], and HO-1 may be induced by inflammation and/or oxidative stress, which generates transcription factors 
activated by p-AKT, then increased the level of $\mathrm{HO}-1$ protein $[44,45]$. Diabetes was associated with oxidative stress; therefore, the level of HO-1 protein evelated. Our results show that luteolin increases the level of HO-1 protein. These results suggest that one of the mechanism of the renoprotective effect of luteolin may be related to increasing HO- 1 expression and elevating antioxidant in diabetic nephropathy.

In conclusion, the results from this study show that luteolin may prevent morphological destruction of kidney due to diabetes mellitus. Further studies are required to determine the exact mechanism of the renoprotective effect of luteolin.

\section{Conclusions}

From the above results, it may be concluded that luteolin may prevent the morphological destruction of the kidney that is associated with diabetes mellitus and may improve the redox balance in the kidney. Therefore, long-term control of antioxidant levels using a luteolin diet may prevent the progression of diabetes mellitus and prevent nephropathy.

\section{References}

[1] F. M. Akhtar and M. R. Ali, "Study of antidiabetic effect of a compound medicinal plant prescription in normal and diabetic rabbits," Journal of the Pakistan Medical Association, vol. 34, pp. 239-244, 1984.

[2] M. Q. Man, Y. Shi, M. Man et al., "Chinese herbal medicine (Tuhuai extract) exhibits topical anti-proliferative and antiinflammatory activity in murine disease models," Experimental Dermatology, vol. 17, no. 8, pp. 681-687, 2008.

[3] F. Firenzuoli and L. Gori, "Herbal medicine today: clinical and research issues," Evidence-Based Complementary and Alternative Medicine, vol. 4, no. 1, pp. 37-40, 2007.

[4] E. Ernst, "Harmless herbs? A review of the recent literature," American Journal of Medicine, vol. 104, no. 2, pp. 170-178, 1998.

[5] S. Jang, K. W. Kelley, and R. W. Johnson, "Luteolin reduces IL6 production in microglia by inhibiting JNK phosphorylation and activation of AP-1," Proceedings of the National Academy of Sciences of the United States of America, vol. 105, no. 21, pp. 7534-7539, 2008.

[6] J. A. Ross and C. M. Kasum, "Dietary flavonoids: bioavailability, metabolic effects, and safety," Annual Review of Nutrition, vol. 22, pp. 19-34, 2002.

[7] M. López-Lázaro, "Distribution and biological activities of the flavonoid luteolin," Mini-Reviews in Medicinal Chemistry, vol. 9, no. 1, pp. 31-59, 2009.

[8] J. M. McCord, "Oxygen-derived free radicals in postischemic tissue injury," New England Journal of Medicine, vol. 312, no. 3, pp. 159-163, 1985.

[9] M. O. Jeroudi, C. J. Hartley, and R. Bolli, "Myocardial reperfusion injury: role of oxygen radicals and potential therapy with antioxidants," American Journal of Cardiology, vol. 73, no. 6, pp. 2B-7B, 1994.

[10] M. Comporti, "Lipid peroxidation and cellular damage in toxic liver injury," Laboratory Investigation, vol. 53, no. 6, pp. 599-623, 1985.
[11] G. Poli, E. Albano, and M. U. Dianzani, "The role of lipid peroxidation in liver damage," Chemistry and Physics of Lipids, vol. 45, no. 2-4, pp. 117-142, 1987.

[12] L. W. Oberley, "Free radicals and diabetes," Free Radical Biology and Medicine, vol. 5, no. 2, pp. 113-124, 1988.

[13] D. Harman, "The aging process," Proceedings of the National Academy of Sciences of the United States of America, vol. 78, no. 11, pp. 7124-7128, 1981.

[14] E. Matteucci and O. Giampietro, "Oxidative stress in families of type 1 diabetic patients," Diabetes Care, vol. 23, no. 8, pp. 1182-1186, 2000.

[15] J. W. Baynes and S. R. Thorpe, "The role of oxidative stress in diabetic complications," Current Opinion in Endocrinology and Diabetes, vol. 3, no. 4, pp. 277-284, 1997.

[16] B. Lipinski, "Pathophysiology of oxidative stress in diabetes mellitus," Journal of Diabetes and Its Complications, vol. 15, no. 4, pp. 203-210, 2001.

[17] H. M. Kubisch, J. Wang, T. M. Bray, and J. P. Phillips, "Targeted overexpression of $\mathrm{Cu} / \mathrm{Zn}$ superoxide dismutase protects pancreatic $\beta$-cells against oxidative stress," Diabetes, vol. 46, no. 10, pp. 1563-1566, 1997.

[18] M. Naziroglu and M. Cay, "Protective role of intraperitoneally administered vitamin $\mathrm{E}$ and selenium on the oxidative defense mechanisms in rats with diabetes induced by streptozotocin," Biol. Stress Elem. Res, vol. 47, pp. 475-488, 2001.

[19] P. Hovind, L. Tarnow, K. Rossing et al., "Decreasing incidence of severe diabetic microangiopathy in type 1 diabetes," Diabetes Care, vol. 26, no. 4, pp. 1258-1264, 2003.

[20] H. Yokoyama, M. Okudaira, T. Otani et al., "Higher incidence of diabetic nephropathy in type 2 than in type 1 diabetes in early-onset diabetes in Japan," Kidney International, vol. 58, no. 1, pp. 302-311, 2000.

[21] H. Ha and H. B. Lee, "Reactive oxygen species as glucose signaling molecules in mesangial cells cultured under high glucose," Kidney International. Supplement, vol. 58, no. 77, pp. S19-S25, 2000.

[22] M. C. Iglesias-De La Cruz, P. Ruiz-Torres, J. Alcamí et al., "Hydrogen peroxide increases extracellular matrix mRNA through TGF- $\beta$ in human mesangial cells," Kidney International, vol. 59, no. 1, pp. 87-95, 2001.

[23] B. Sharma, G. Viswanath, R. Salunke, and P. Roy, "Effects of flavonoid-rich extract from seeds of Eugenia jambolana (L.) on carbohydrate and lipid metabolism in diabetic mice," Food Chemistry, vol. 110, no. 3, pp. 697-705, 2008.

[24] K. Tikoo, D. N. Tripathi, D. G. Kabra, V. Sharma, and A. B. Gaikwad, "Intermittent fasting prevents the progression of type I diabetic nephropathy in rats and changes the expression of Sir2 and p53," FEBS Letters, vol. 581, no. 5, pp. 1071-1078, 2007.

[25] K. Tikoo, D. K. Bhatt, A. B. Gaikwad, V. Sharma, and D. G. Kabra, "Differential effects of tannic acid on cisplatin induced nephrotoxicity in rats," FEBS Letters, vol. 581, no. 10, pp. 2027-2035, 2007.

[26] N. Yahagi, H. Shimano, A. H. Hasty et al., "Absence of sterol regulatory element-binding protein-1 (SREBP-1) ameliorates fatty livers but not obesity or insulin resistance in Lep(ob)/Lep(ob) mice," Journal of Biological Chemistry, vol. 277, no. 22, pp. 19353-19357, 2002.

[27] J. D. Ahn, R. Morishita, Y. Kaneda et al., "Transcription factor decoy for AP-1 reduces mesangial cell proliferation and extracellular matrix production in vitro and in vivo," Gene Therapy, vol. 11, no. 11, pp. 916-923, 2004. 
[28] M. Dunlop, "Aldose reductase and the role of the polyol pathway in diabetic nephropathy," Kidney International. Supplement, vol. 58, no. 77, pp. S3-S12, 2000.

[29] M. Mohora, B. Vîrgolici, F. Paveliu, D. Lixandru, C. Muscurel, and M. Greabu, "Free radical activity in obese patients with type 2 diabetes mellitus," Romanian Journal of Internal Medicine, vol. 44, no. 1, pp. 69-78, 2006.

[30] K. Kedziora-Kornatowska, S. Szram, T. Kornatowski, L. Szadujkis-Szadurski, J. Kedziora, and G. Bartosz, "Effect of vitamin $\mathrm{E}$ and vitamin $\mathrm{C}$ supplementation on antioxidative state and renal glomerular basement membrane thickness in diabetic kidney," Nephron Experimental Nephrology, vol. 95, no. 4, pp. e134-e143, 2003.

[31] C. Y. Chen, W. H. Peng, K. D. Tsai, and S. L. Hsu, "Luteolin suppresses inflammation-associated gene expression by blocking NF- $\kappa \mathrm{B}$ and AP-1 activation pathway in mouse alveolar macrophages," Life Sciences, vol. 81, no. 23-24, pp. 1602-1614, 2007.

[32] C. Hu and D. D. Kitts, "Luteolin and luteolin-7-O-glucoside from dandelion flower suppress iNOS and COX-2 in RAW264.7 cells," Molecular and Cellular Biochemistry, vol. 265, no. 1-2, pp. 107-113, 2004.

[33] S. Jang, K. W. Kelley, and R. W. Johnson, "Luteolin reduces IL6 production in microglia by inhibiting JNK phosphorylation and activation of AP-1," Proceedings of the National Academy of Sciences of the United States of America, vol. 105, no. 21, pp. 7534-7539, 2008.

[34] N. D. Vaziri, "Dyslipidemia of chronic renal failure: the nature, mechanisms, and potential consequences," American Journal of Physiology, vol. 290, no. 2, pp. F262-F272, 2006.

[35] M. Sugano, H. Yamato, T. Hayashi et al., "High-fat diet in low-dose-streptozotocin-treated heminephrectomized rats induces all features of human type 2 diabetic nephropathy: a new rat model of diabetic nephropathy," Nutrition, Metabolism and Cardiovascular Diseases, vol. 16, no. 7, pp. 477-484, 2006.

[36] H. Makino, I. Tanaka, M. Mukoyama et al., "Prevention of diabetic nephropathy in rats by prostaglandin $\mathrm{E}$ receptor EP1-selective antagonist," Journal of the American Society of Nephrology, vol. 13, no. 7, pp. 1757-1765, 2002.

[37] M. D. Breyer, E. Böttinger, F. C. Brosius III et al., "Mouse models of diabetic nephropathy," Journal of the American Society of Nephrology, vol. 16, no. 1, pp. 27-45, 2005.

[38] S. Z. Sun, Y. Wang, Q. Li, Y. J. Tian, M. H. Liu, and Y. $\mathrm{H}$. Yu, "Effects of benazepril on renal function and kidney expression of matrix metalloproteinase-2 and tissue inhibitor of metalloproteinase-2 in diabetic rats," Chinese Medical Journal, vol. 119, no. 10, pp. 814-821, 2006.

[39] A. Agarwal and H. S. Nick, "Renal response to tissue injury: lessons from heme oxygenase-1 gene ablation and expression," Journal of the American Society of Nephrology, vol. 11, no. 5, pp. 965-973, 2000.

[40] S. W. Ryter, J. Alam, and A. M. K. Choi, "Heme oxygenase1/carbon monoxide: from basic science to therapeutic applications," Physiological Reviews, vol. 86, no. 2, pp. 583-650, 2006.

[41] S. W. Ryter, H. P. Kim, K. Nakahira, B. S. Zuckerbraun, D. Morse, and A. M. K. Choi, "Protective functions of heme oxygenase-1 and carbon monoxide in the respiratory system," Antioxidants and Redox Signaling, vol. 9, no. 12, pp. 21572173, 2007.

[42] D. P. Brazil, Z. Z. Yang, and B. A. Hemmings, "Advances in protein kinase B signalling: AKTion on multiple fronts,"
Trends in Biochemical Sciences, vol. 29, no. 5, pp. 233-242, 2004.

[43] K. Naruse, C. Rask-Madsen, N. Takahara et al., "Activation of vascular protein kinase C-beta; inhibits Akt-dependent endothelial nitric oxide synthase function in obesityassociated insulin resistance," Diabetes, vol. 55, no. 3, pp. 691698, 2006.

[44] G. Sambuceti, S. Morbelli, L. Vanella et al., "Diabetes impairs the vascular recruitment of normal stem cells by oxidant damage, reversed by increases in pAMPK, heme oxygenase-1, and adiponectin," Stem Cells, vol. 27, no. 2, pp. 399-407, 2009.

[45] Z. Han, S. Varadharaj, R. J. Giedt, J. L. Zweier, H. H. Szeto, and B. R. Alevriadou, "Mitochondria-derived reactive oxygen species mediate heme oxygenase-1 expression in sheared endothelial cells," Journal of Pharmacology and Experimental Therapeutics, vol. 329, no. 1, pp. 94-101, 2009. 


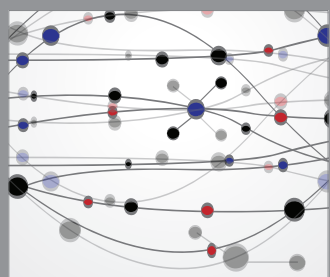

The Scientific World Journal
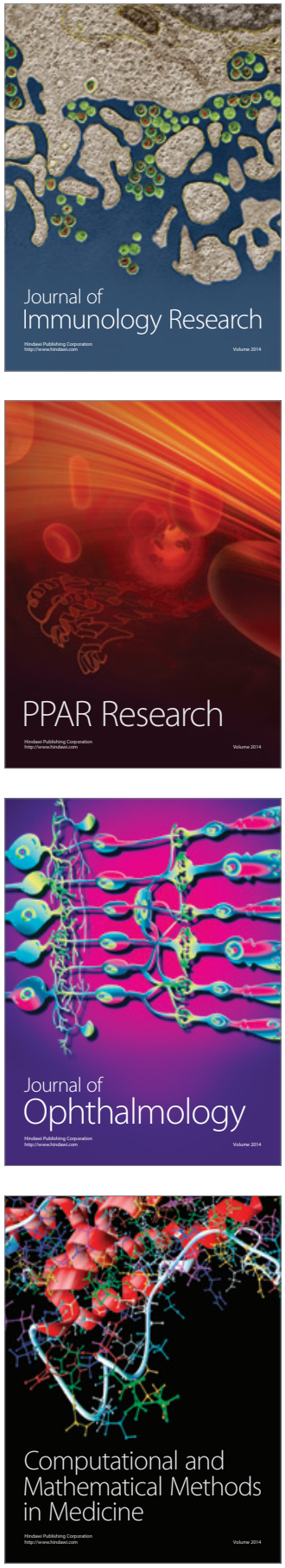

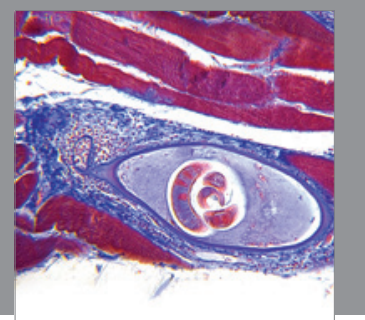

Gastroenterology

Research and Practice
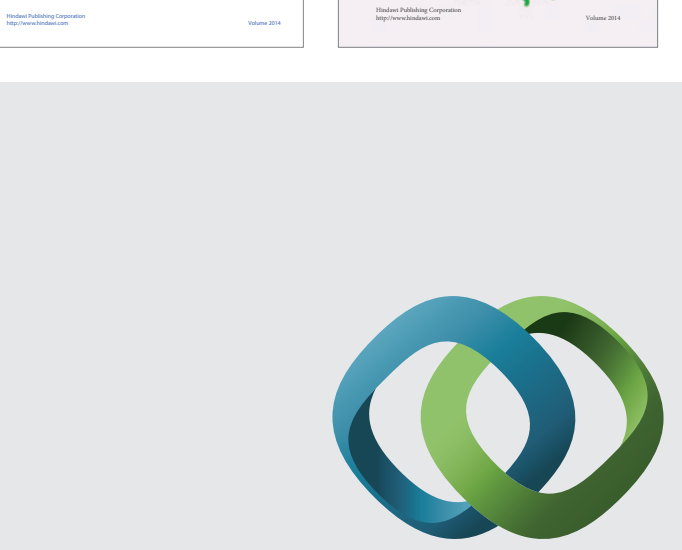

\section{Hindawi}

Submit your manuscripts at

http://www.hindawi.com
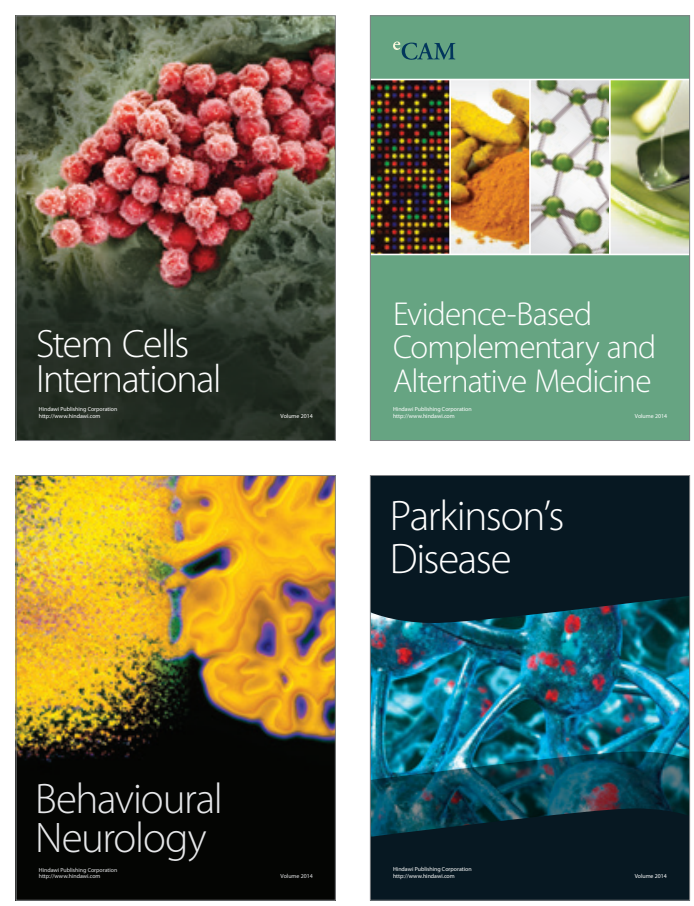

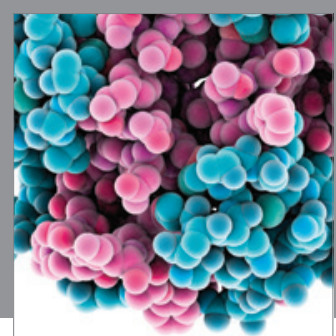

Journal of
Diabetes Research



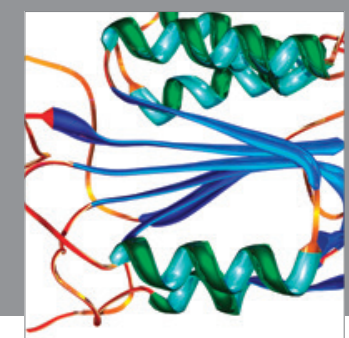

Disease Markers
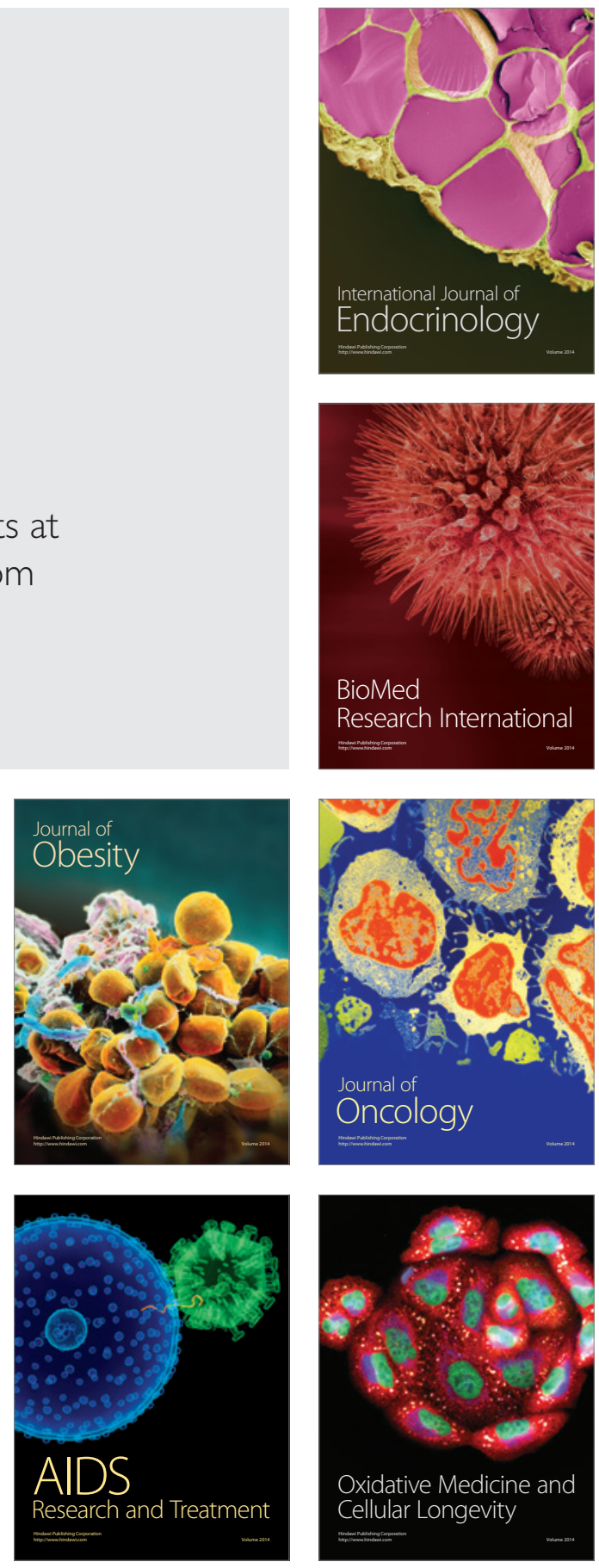